\title{
POLARISED SEGREGATION IN THE POLLEN MOTHER CELLS OF A STABLE TRIPLOID
}

\author{
S. SMITH-WHITE \\ Museum of Technology and Applied Science, Sydney
}

Received 2.ix.47

INTRODUCTION

The Australasian family of the Ericales, the Epacridacex, are known to the Author in their chromosome numbers by only a single report, that given by Samuelson (1913) for Epacris impressa, cited by Gaiser (1930). A difference of opinion in papers by Hagerup (1928) and Wanscher (1934) concerning the probable basic chromosome number in the Ericales, suggested that a survey of the Epacridaceæ might be of interest, and the results of such a survey are being published elsewhere (Smith-White, r947a). In this survey a triploid species of Leucopogon was discovered in which chromosome behaviour at meiosis is peculiar and of general cytological interest.

\section{MATERIALS AND METHODS}

Leucopogon juniperinus. $\mathrm{R} . \mathrm{Br}$. is a species occurring abundantly on shale-soil areas in the vicinity of Sydney. Bentham (1869) also records it from Moreton Bay, Queensland, and doubtfully from the Upper Macalister River, Victoria. These occurrences, however, would appear to be geographically isolated from one another, and the present study concerns only the species in the Port Jackson area. Plants have been examined from four localities within the area, viz. Lane Cove River, Gordon, Kuringai and Yagoona, all within 12 miles of Sydney.

Mitotic chromosomes were drawn from aceto-lacmoid crushes of young ovules, following maceration in $\mathrm{HCl}$-lacmoid as in the schedule given by Darlington and La Cour (1942), and made permanent in Euparal. Meiosis in pollen mother cells was studied from acetocarmine crushes, which have also been made permanent. For studies of fertility, pollen from mature anthers, ready to dehisce, was mounted in a special dextrin-sorbitol-acid fuchsin stain mountant ( $c f$. SmithWhite, $1947 b$ ). Chromosome drawings were made with a camera lucida at an initial magnification of ca. 3900, and have been reduced for reproduction to ca. 2600 .

\section{OBSERVATIONS}

The mitotic chromosomes. The somatic chromosome number for the species is 12 (fig. I ; pl. I, fig. I). At metaphase in ovule mitoses, the chromosomes are rod-shaped bodies, of uniform length (ca. 2.7- 
$3 \cdot 0 \mu$ ), and all show median centric constrictions. So far it has not been possible to observe any characteristic morphological differences between the chromosomes.

Although the genus Leucopogon shows considerable variation in chromosome number $(n=4,6$, 10, 12, 24 (Smith-White, 1947a)), two closely related species, $L$. setiger and $L$. esquamatus, have a haploid complement of 4 , so that $L$. juniperinus is apparently triploid in constitution.

Meiosis in the pollen mother cells. At the first metaphase the pollen mother cells regularly show 4 bivalents and 4 univalents. No multivalents, and never more or less than 4 bivalents, were found in $5^{86}$ pollen mother cells from five plants (fig. 2 ; pl. I, fig. 2). Pairing of the bivalents is very uniform, with a rather high chiasma-frequency, a majority being united on both sides of the centromere. In one plant (No. o) in which I 22 I-M cells were studied (488 bivalents), 412 bivalents, or 84.4 per cent., were associated on both sides of the centromere. Uniform association and regular high chiasma-frequency is an indication of homozygosity and lack of difference between the pairing chromosomes.

The extraordinary regularity of the chromosome associations suggests that the species is a triploid on a basic haploid set of 4 chromosomes, and that its constitution may be represented by the formula-

\section{A A B B C G D D E F G H}

in which each letter represents a whole chromosome. This means that the species is probably of hybrid origin, and that the paired chromosomes $\mathrm{A}, \mathrm{B}, \mathrm{C}$ and $\mathrm{D}$ are derived from one parent, and that the unpaired chromosomes $\mathrm{E}, \mathrm{F}, \mathrm{G}$ and $\mathrm{H}$ are derived from another parental species, sufficiently remote phylogenetically from the first to exclude the occurrence of multivalent associations between the two sets. Such complete failure of chromosome pairing has been demonstrated in many artificial diploid species hybrids, and the condition is essentially similar to that found in triploid hybrids, in which the chromosome set from one parent is present in the diploid number. ( $c f$. Darlington, 1937, pp. 210-212). Such a doubling of one of the two chromosome sets could be derived either from an unreduced diploid gamete, from backcrossing to one parent, or if one of the parents was autotetraploid in constitution.

The behaviour of the univalents. In general, the behaviour of univalents on the spindle during the first meiotic division is well understood (Darlington, I937, p. 410 ; Kihara, 1931 ; Ribbands, 1937). Usually they are late in movement to the equatorial plate at $\mathrm{Mr}$, and if the anaphase division of the bivalents occurs before their arrival at the plate, they may be included in one or other anaphase group at the poles. In this case their distribution is random. On the other hand, if they reach the plate, they tend to remain there 
FIgs. I-9. $-\times$ ca. 2000. I. Somatic chromosomes in ovule tissue. 2. MI in polar view, showing the bivalent plate. 3. $\mathrm{M}_{\mathrm{I}}$, in side view, showing a 2-2 distribution of the univalents. Note how the univalents are forced to the extremities of the poles of the spindle. 4. $\mathrm{MI}_{\mathrm{I}}$, in side view, showing a $\mathrm{I}-3$ distribution of the univalents. One univalent at the bottom of the picture is out of focus. $5 . \mathrm{Mr}$ in side view, showing all 4 univalents at one end of the spindle. 6. M2, showing unequal plates of 4 and 8 chromosomes. 7. T2, showing a second division bridge. 8. T2, showing laggard chromosomes, possibly the result of misdivision. 9. A pollen mother cell showing the rearrangement of the four microspore nuclei.

Figs. 1o and II.- $\times$ ca. 90o. 10. The pollen mother cell shortly after cytokinesis. II. Young pollen grain in the binucleate stage (section).

Fig. 12. $-X$ ca. 2 10. Mature pollen. 

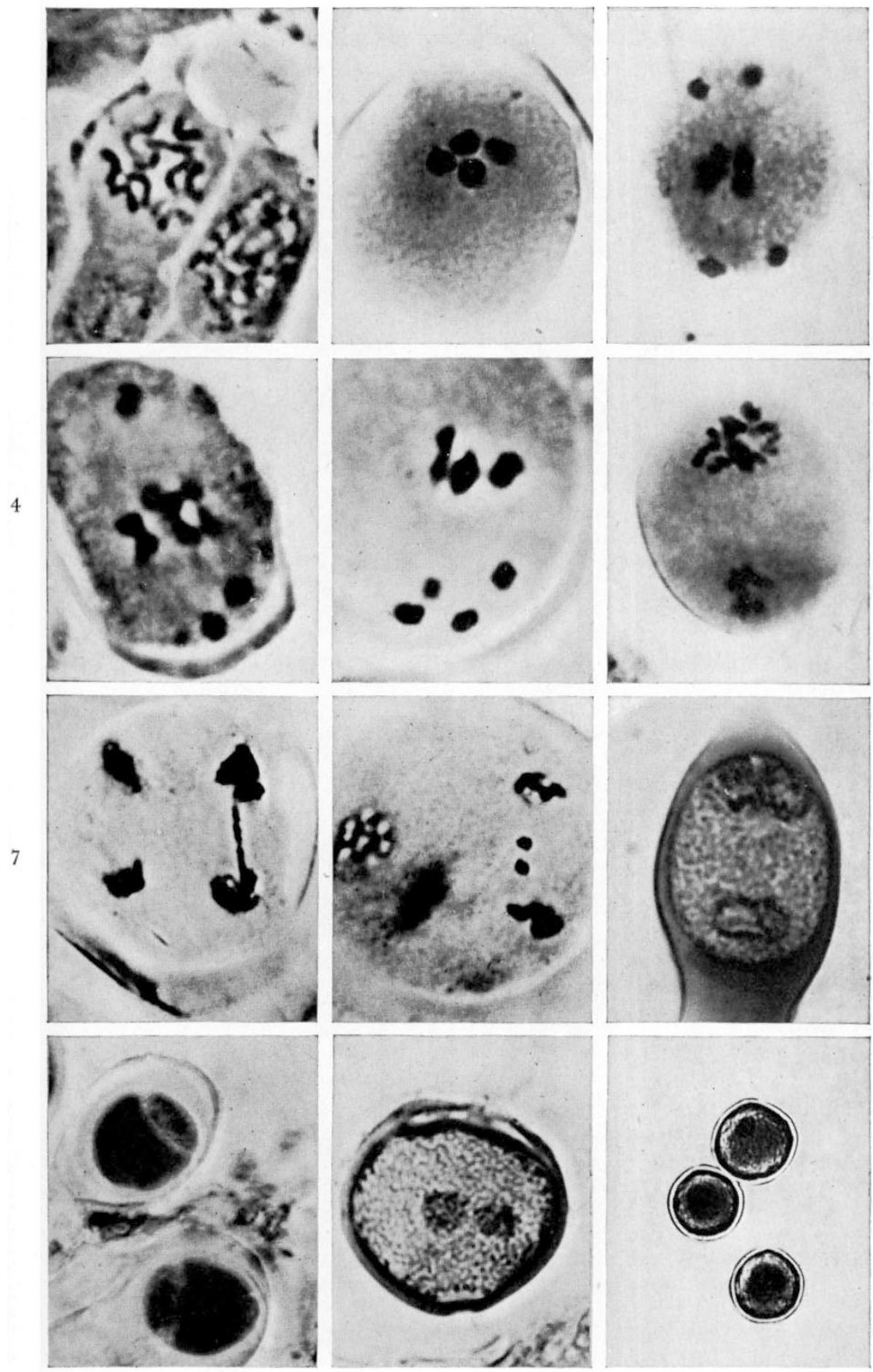

IO

I I 
after the anaphase separation of the bivalents, and to divide into daughter chromatids, which follow the daughter chromosomes of the bivalents to the poles. At the second division such divided uni-

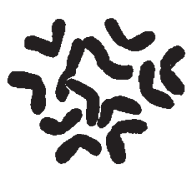

FIG. I.

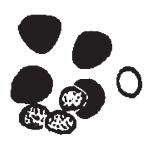

FIG. 2.

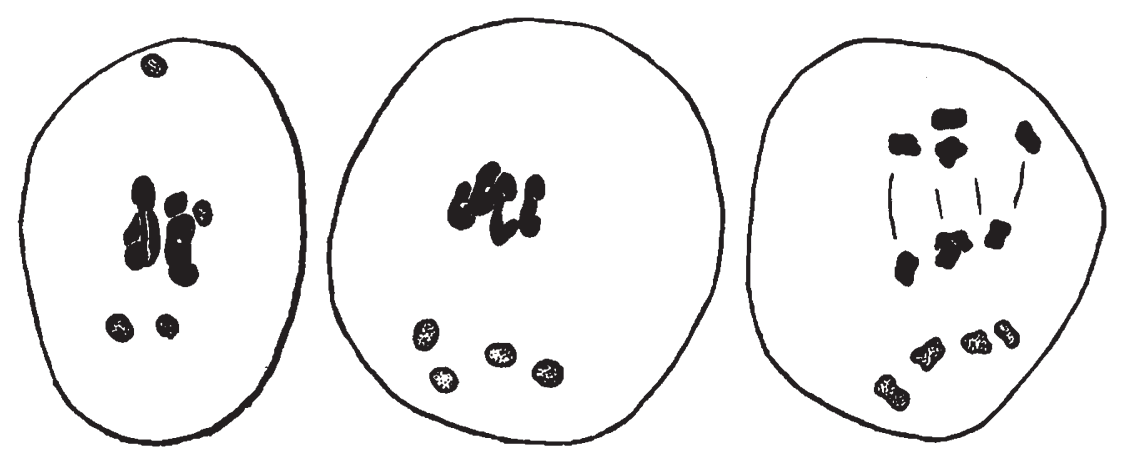

Fig. 3.

FIG. 4.

Fig. 5.

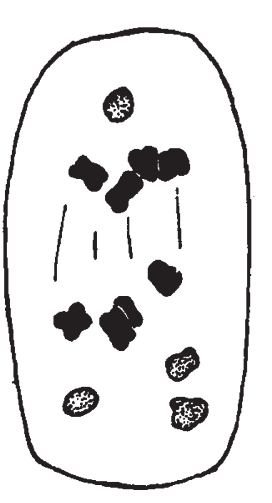

Fig. 6.

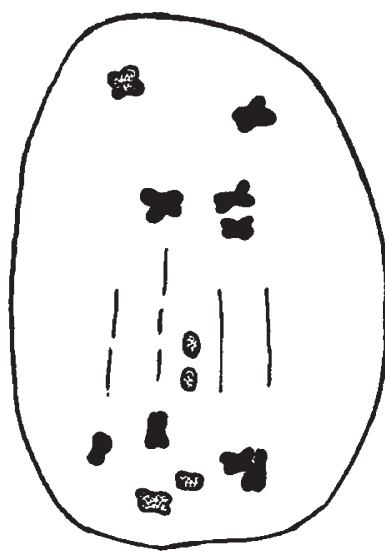

Fig. 7 .

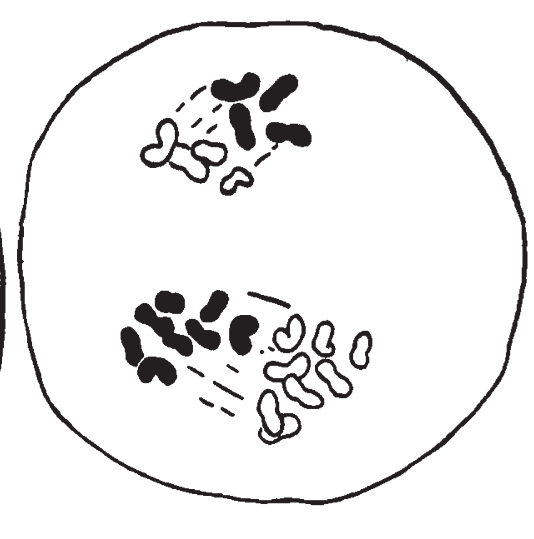

Fig. 8.

Figs. 1-8.-Leucopogon juniperinus $\times 2600$. I. Somatic chromosomes in ovule crush $2 n=12$. 2. $\mathrm{I}-\mathrm{M}$ in pollen mother cell, polar view, three univalents are above, and one is below the bivalent plate. 3. I-M, showing a I-I-2 distribution of univalents. 4. I-M, with the more frequent $0-0-4$ distribution of univalents. 5. I-A, with the four univalents moving to the one pole ahead of the paired chromosomes. 6. I-A, with a I-3 distribution of the univalents. 7. I-A, showing the (comparatively rare) division of a univalent. 8. 2-A, showing small and large spindles of 4 and 8 chromosomes respectively.

valents are usually randomly distributed to the poles of the second anaphase spindles. Where univalents are present, the regularity of the meiotic division is upset, and a majority of the microspore nuclei are of unbalanced constitution. 
In L. juniperinus the four univalent chromosomes show an unusual behaviour. At MI they usually lie off the equatorial plate, towards the poles of the spindle (figs. 3 and 4 ; pl. I, figs. 3,4 and 5). In a minority of cells one or more univalents may have reached the equator at this stage, when such univalents lie on the edge of the bivalent plate. Of 586 cells at $M_{I}$, for which data are given in table 1 , only 152, or 25.9 per cent., showed univalents in such a position.

The most remarkable feature in the behaviour of the univalents is their non-random distribution (table I). In a majority of cells,

TABLE I

Distribution of the univalents at $M I$ in $\mathrm{L}$. juniperinus

\begin{tabular}{|c|c|c|c|c|c|}
\hline \multirow{2}{*}{ Plant no. } & \multicolumn{4}{|c|}{ Type of distribution } & \multirow{2}{*}{ Tota } \\
\hline & 0.4 & $1-3$ & $2-2$ & Incomplete & \\
\hline $\begin{array}{l}0 \\
1 \\
3 \\
4 \\
5\end{array}$ & $\begin{array}{l}52 \\
54 \\
21 \\
44 \\
71\end{array}$ & $\begin{array}{l}23 \\
32 \\
12 \\
33 \\
36\end{array}$ & $\begin{array}{r}7 \\
12 \\
7 \\
19 \\
11\end{array}$ & $\begin{array}{r}44 \\
39 \\
9 \\
32 \\
28\end{array}$ & $\begin{array}{r}126 \\
137 \\
49 \\
128 \\
146\end{array}$ \\
\hline Total & 242 & 136 & $5^{6}$ & 152 & $5^{86}$ \\
\hline Expected nos. (random basis) & $54 \cdot 25$ & $217 \cdot 00$ & ${ }_{162} \cdot 75$ & $\ldots$ & $\ldots$ \\
\hline
\end{tabular}

$\chi^{2}=75^{\circ} \cdot 02 . \quad n=2 . \quad p \ll 0 \cdot 001$.

all four univalents pass to the one pole (fig. $4 ;$ pl. I, fig. 5), and even at mid-metaphase they are then placed at the extreme end of the spindle, near the edge of the cell, but usually lie well apart. Ignoring the 152 cells in which univalents lie near the equator, and whose final distribution cannot be determined, the distribution is seen to differ widely from that expected on a random basis. $\left(\chi^{2}=75^{\circ} 02\right.$, $p \ll$ o.oor.)

The cause of this polarity in univalent distribution is not apparent, but its result is clear. A majority of the pollen mother cells at $\mathrm{M}_{2}$ show unequal plates, most frequently one with 4 and the other with 8 chromosomes, the larger plate containing all the unpaired chromosomes (table 2 ; pl. I, fig. 6).

Division of univalents on the equator of the AI spindle, after the separation of the bivalent chromosomes (fig. 7) is rare, as indicated by the frequency of chromosome numbers at $\mathbf{M}_{2}$, given in table 2. This would be expected as an incidental result of the polarity in univalent behaviour.

At anaphase, after the separation of the bivalent chromosomes, the univalents are first to reach the poles (figs. 5 and 6). At this stage 
the repulsion between the chromatid-arms is very evident in all chromosomes.

TABLE 2

Distribution of chromosomes at $M_{2}$ in L. juniperinus

\begin{tabular}{|l|c|c|c|c|c|c|c|}
\hline & \multicolumn{5}{|c|}{ Type of distribution } & \multirow{2}{*}{ Total } \\
\cline { 1 - 6 } & $4-8$ & $5-7$ & $5 \frac{1}{2}-6 \frac{1}{2}$ & $6-6$ & $5-6-(1) \dagger$ & \\
\hline Plant no. 1 observed frequency &. & 15 & 8 & 2 & 3 & 1 & 29 \\
Expected frequency (random basis) &. & $3 \cdot 25$ & $13 \cdot 00$ & $\ldots$ & $9 \cdot 75$ & $\ldots$ & $\ldots$ \\
\hline
\end{tabular}

\footnotetext{
* Due to division of univalent at $\mathrm{Mr}$.

† Chromosome lost in cytoplasm.

$\chi^{2}=49.07 . \quad n=2 . \quad p \ll 0.001$.
}

Apart from the uneven size of the two plates, the second meiotic division is usually normal (fig. 8). Occasionally, however, bridges (pl. I, fig. 7) or laggards (pl. I, fig. 8) are seen. The former indicate that structurally the bivalent chromosomes are not completely homozygous, but that they differ at least in respect of segmental inversions. The laggards shown in pl. I, fig. 8, may represent a case of misdivision of a centromere, since they are smaller than the other chromosomes. Darlington (1939a, 1940) has shown that the centromeres of univalents which have divided at first anaphase are unable to divide normally at second anaphase, and are consequently liable to misdivision. Several cases of such possible misdivision have been observed in L. juniperinus.

Pollen development. Pollen development is of a peculiar type, also found in other species of Leucopogon, in Styphelia, and other genera of the Styphelex. This type of development has been described elsewhere (Smith-White, I947a), as the "Styphelia" or "S" type, as distinct from the " tetrad " type of pollen development characteristic of the Ericales generally. The four telophasic microspore nuclei do not show uniform behaviour. At first, having a tetrahedral or quartite arrangement, they assume, prior to cytokinesis, a grouped arrangement, in which three nuclei are clustered at one end of the cell, and a single nucleus at the other (pl. I, fig. 9). The pollen mother cell is then divided into three small and one large microspore (pl. I, fig. Io). The large microspore is the only one to continue development. The other three degenerate, or become crushed out of existence (pl. I, fig. I I), so that the mature pollen consists of "single" grains, of the type described by Brough (1924) for Styphelia (pl. I, fig. I2).

It has not yet been determined whether the functional microspore of each "tetrad" is of any particular chromosome constitution, but from size comparisons of the nuclei, it is suggested that it may be one of the 8 chromosome nuclei. The rapid thickening of the wall of the 
developing pollen grain offers some difficulty in the examination of the pollen grain mitosis. Very occasionally "double" pollen grains, resulting from the development of two microspore nuclei, are found. Their frequency, however, is almost negligible, only three cases being observed in a slide containing over 2000 pollen grains.

Pollen fertility. Pollen fertility is variable, with a considerable proportion of aborted grains, but it must be regarded as unusually high for a triploid. The data given in table 3 indicate that significant variations in pollen fertility may occur between plants, or even between flowers on the same plant, and it is probable that pollen development and fertility are very susceptible to environmental, and particularly, temperature conditions.

L. juniperinus is abundantly seed-fertile. In fact it sets a much higher proportion of fruits than its diploid relatives $L$. setiger and $L$. esquamatus, and it is morphologically a uniform and distinctive species.

TABLE 3

Pollen fertility in Leucopogon juniperinus

Per cent. good pollen

\begin{tabular}{|c|c|c|c|c|c|c|c|c|c|c|c|}
\hline Plant & \multicolumn{5}{|c|}{ Slide $(a)$} & \multicolumn{5}{|c|}{ Slide $(b)$} & \multirow{2}{*}{$\mathbf{M}$} \\
\hline No. & I & 2 & 3 & 4 & $m$ & I & 2 & 3 & 4 & $m$ & \\
\hline $\begin{array}{l}1 \\
2 \\
3 \\
4 \\
5\end{array}$ & $\begin{array}{r}31 \\
36 \\
8 \\
65 \\
70\end{array}$ & $\begin{array}{l}31 \\
43 \\
18 \\
76 \\
78\end{array}$ & $\begin{array}{l}45 \\
40 \\
30 \\
67 \\
67\end{array}$ & $\begin{array}{l}33 \\
46 \\
21 \\
67 \\
60\end{array}$ & $\begin{array}{l}35 \cdot 00 \\
41 \cdot 25 \\
19 \cdot 25 \\
68 \cdot 75 \\
68 \cdot 75\end{array}$ & $\begin{array}{l}46 \\
58 \\
10 \\
64 \\
68\end{array}$ & $\begin{array}{r}42 \\
60 \\
5 \\
71 \\
70\end{array}$ & $\begin{array}{l}47 \\
76 \\
12 \\
65 \\
74\end{array}$ & $\begin{array}{r}41 \\
47 \\
9 \\
63 \\
61\end{array}$ & $\begin{array}{r}44 \cdot 00 \\
60 \cdot 25 \\
9 \cdot 00 \\
65 \cdot 75 \\
68 \cdot 25\end{array}$ & $\begin{array}{l}39^{\cdot} 5^{0} \\
5^{\circ} \cdot 75 \\
14 \cdot 13 \\
67 \cdot 25 \\
68 \cdot 5^{\circ}\end{array}$ \\
\hline Gene & 10 & - & & & $\ldots$ & - & & & - & ... & $4^{8 \cdot 25}$ \\
\hline
\end{tabular}

Analysis of variance

\begin{tabular}{|c|c|c|c|c|c|c|}
\hline & SS & $\mathrm{DF}$ & MS & $\mathbf{F}$ & SE & $\begin{array}{l}\text { Sign difference } \\
\text { at } 5 \text { per cent. } \\
\text { point }\end{array}$ \\
\hline Total & $18,54^{2} \cdot 75$ & 39 & & & & $\cdots$ \\
\hline Between plants. & $15,858.875$ & 4 & $3,964 \cdot 719$ & $17 \cdot 8 \dagger$ & $\pm 5 \cdot 31$ & $19 \cdot 3$ \\
\hline Slides * & $1,112.625$ & 5 & $222 \cdot 525$ & $\ldots$ & $\ldots$ & $\cdots$ \\
\hline Error . & $1,571 \cdot 25^{\circ}$ & 20 & $78 \cdot 5625$ & $\ldots$ & $\ldots$ & $\ldots$ \\
\hline
\end{tabular}

* Used as error control.

† Exceeds the I per cent. point of $F$.

\section{DISCUSSION}

The high fertility of the species may simply mean that it is fully apomictic, as are so many triploids and odd-numbered polyploids in nature (Darlington, I937, p. 468). Apomictic polyploids, however, 
usually show extreme irregularity of meiosis, particularly in the pollen mother cells, resulting in polysporous tetrads and highly infertile pollen. With such a method of reproduction, it is difficult to imagine the evolution of the unusual stabilised meiosis. which has been described. Such stabilisation could offer selective evolutionary advantage only if the pollen is involved in seed production, and it could be developed only by adaptation in the course of sexual reproduction (Darlington, 1937, p. 414). The only known comparable case is the condition of "semi-apomixis" found in the Canina section of Rosa (Täckholm, I922 ; Hurst, 193I), in which the egg carries a number of univalents, which have been distributed in a polarised manner. The present case may be similar, except that it concerns pollen formation, and the extra univalents may be carried by the pollen. Genetically the system has a similar result, in permitting a hybrid species to breed true, but the species does not seem to be divided into the numerous interrelated but true-breeding forms that occur in the Canina.

Several cases of polarity in chromosome behaviour have been reported in the past. Morgan, Bridges and Sturtevant (1925) showed that in triploid Drosophila the distribution of univalents may not be according to chance, but that certain combinations of sex chromosomes and autosomes are formed more often than others. Sturtevant (1936) found that in triplo-IV females of Drosophila melanogaster the segregation of the three chromosomes IV was not random, and that the segregation of the third chromosome was determined by a property of the other pair. Darlington (1940) has shown that the segregation of supernumerary sex chromosomes in Cimex may be preferential with respect to the $\mathrm{Y}$ chromosome.

In these cases, the differential segregation appears to be determined by the chiasma relationships or other properties of the chromosomes themselves, or by a property of the spindle mechanism, rather than by any polarisation of the cell as a whole. Rhoades (1942) found that in the embryo-sac mother cell in maize heterozygous for an abnormal heterochromatic segment of chromosome io, the abnormal chromosome passes to the lower (chalazal) end of the spindle most frequently, and Catcheside (1944) has shown a clear case of non-random segregation in the ascomycete Bombardia lunata, which he ascribes to the existence of a gradient in the cell. Renner (1940) has also discussed the relation of heterogamy and polarised segregation in Denothera.

There are several possible explanations of the polarity in behaviour of the univalents in Leucopogon juniperinus. First, the distribution might be a mechanical effect consequent on the persistence through meiotic prophase of the chromosome arrangement derived from the preceding mitotic telophase. (a) Chromosome movement during meiotic prophase, which must be considerable, would tend to eliminate any such polarisation. (b) A similar behaviour would be expected in other plants with univalents, and this is not so. (c) With 
such a derivation, the polarity of the pollen mother cells would be in opposed pairs which are not found.

Secondly, the polarity in movement might be the consequence of a gradient in the cell. Catcheside (loc. cit.) has pointed out that the orientation and differential segregation of chromosomes involves two kinds of inequality : (i) a gradient in the cell as a whole, and (ii) a difference possessed by the chromosomes showing the bias, and capable of directing them with reference to the cell gradient. It is significant that a morphological polarity in the pollen mother cells is apparently normal for most species of Leucopogon, for Styphelia and for related genera. This polarity controls the unusual type of pollen development described. It may be in some way analogous to the gradient which determines the development of the embryo-sac from a particular one, usually that at the chalazal end, of the row of four megaspores. This gradient provides the first of Catcheside's requirements. On the other hand, it appears to be intracellular in nature, since the pollen mother cells show a random arrangement in the anther as a whole, as seen in longitudinal section. The functional pollen grain of each " tetrad" may face in any direction with reference to the axis of the anther. Since the pollen mother cells have no obvious morphological "base," it is difficult to fit the explanation offered by Catcheside for Bombardia. He was dealing with a situation in which there was a definite linear arrangement of the nuclei, but here no such arrangement exists.

The condition in $L$. juniperinus also shows interesting similarities and differences as compared with the case in maize, in which the non-random segregation of a heterozygous bivalent is controlled by an abnormal heterochromatic segment in one of the chromosomes. It is possible that in both plants a similar action of heterochromatin, in directing the movement of chromosomes along the gradient present in the cell, is being manifested. In L. juniperinus the univalents are similar in staining behaviour to the bivalents at all stages. There is, however, in all chromosomes, a distinct region close to the centromere which frequently fails to stain, especially at second metaphase, and a relation between these heterochromatic segments and the segregation of the univalents cannot be excluded. In maize, the effect of the heterochromatin is shown in bivalents heterozygous for the heterochromatic segment. Differential segregation could not be shown by a bivalent homozygous either for the presence or absence of the segment, since it is dependent upon unbalance between the component chromosomes. With the univalents of Leucopogon, it is possible that heterochromatic or other segments, not being balanced against similar segments as in bivalents, may act in the same way, directing the univalents in a definite direction with respect to the cell gradient. It is impossible to say whether any particular segment is responsible for this direction, but a comparison of the behaviour of univalents with different distributions of heterochromatin in this 
or other related species might provide evidence of whether this directional property is characteristic of heterochromatin. In order to test this hypothesis it is proposed to undertake the synthesis of new allotriploids in Leucopogon and Styphelia.

It is not known whether the four univalents tend to be associated with any particular daughter bivalent or group of daughter bivalents. Any polarity in the behaviour of the bivalents could be determined cytologically only in the presence of visible differences between the chromosomes, or genetically by the use of plants heterozygous for marker genes. Genetically the species is totally unknown.

L. juniperinus demands further cytological study. It is necessary to determine the exact constitution of the functional pollen grains, and the meiotic behaviour in the embryo-sac mother cell. Brough (I924) has shown that the normal development of the embryo-sac from the chalazal megaspore, typical of most Angiosperms, is replaced in Styphelia longifolia by development of the megaspore at the micropylar end of the linear tetrad; the same condition is to be expected in Leucopogon. An attempt at the resynthesis of the species would be desirable, and its probable parents may be found amongst those species of Leucopogon, or even Styphelia, which have a diploid number of 8 . It would be of interest to know the cytological constitution of the species in its occurrence near Brisbane, Queensland, especially if its origin there should prove independent of its origin in the Sydney district.

\section{SUMMARY}

I. An unusual case of a stabilised triploid species, L. juniperinus, with a somatic number of 12 , has been described. The reduction divisions in the pollen mother cells show great regularity, with the formation of 4 bivalents and 4 univalents.

2. Polarity in the distribution of the univalents is pronounced, all four usually going to the same end of the pollen mother cell. This polarity, correlated with an unusual type of pollen development, and with pollen of moderate fertility, suggests that the species is semiapomictic. It presents a condition analogous with that known for Rosa canina except that the extra univalent chromosomes may be carried by the pollen.

3. The polarity in univalent distribution is considered to be a direct consequence of allotriploidy superimposed upon the intracellular polarity which controls the method of pollen development.

4. The species is considered to be of hybrid origin, and to have achieved a true-breeding condition and reasonable fertility by this form of semiapomixis.

Acknowledgment.-The author wishes to express his gratitude to Dr H. N. Barber for helpful discussion of the problem, and for criticism of the text. Acknowledgment is also due to the Trustees and the Director of the Museum of Technology and Applied Science for the provision of facilities for the work. 


\section{REFERENCES}

BENTHAM, G. I869.

Flora Australiensis 4 .

London : Lovell, Reeve.

BROUGH, P. 1924 .

Studies in the Epacridaceæ. (i) The life history of Styphelia longifolia. R. Br.

P. Linn. Soc. N.S.W. $49,162-178$.

CATChESIDE, D. G. I 1944.

Polarised segregation in an Ascomycete.

Ann. Bot. N.S. 8, $119-130$.

DARLINGTON, C. D. 1937.

Recent advances in cytology.

London : Churchill.

DARLINGTON, C. D. I939a.

Misdivision and the genetics of the centromere.

7. Genet. 37, 341-364.

DARLINGTON, C. D. $1939 b$.

The genetical and mechanical properties of the sex chromosomes. V. Cimex and the Heteroptera.

7. Genet. 39, $101-137$.

DARLINGTON, C. D. 1940 .

The origin of Isochromosomes.

7. Genet. 39, 35 I-36 I.

DARLINGTON, c. D., AND LA COUR, L. F. 1942.

The handling of chromosomes.

London : Allen and Unwin.

GAISER, L. O. 1930.

Chromosome numbers in the angiosperms. II.

Bibliog. Genet. 6, I 7 I-41 2.

HAGERUP, O. 1928.

Morphological and cytological studies in the Bicornes.

Dansk. Bot. Arkiv. 6, I-26.

HURST, c. C. 1931.

Embryo-sac formation in diploid and polyploid species of Roseæ.

P.R.S. (B) $\log , 126-148$.

KIHARA, H. I93I.

Genomanalyse bei Triticum und Aegilops II Aegilotricum and Aegilops cylindrea.

Cytologia 2, 106-156.

MORGAN, T. H., BRIDGES, C. H., AND STURTEVANT, A. H. 1925 .

The genetics of Drosophila.

Bibliog. Genet. 2, I-262.

RENNER, O. I 1940 .

Kurze Mitteilungen über Oenothera, IV. Über die Beziehung zwischen Heterogamie und Embryo-sac entwicklung u.s.w.

Flora, N.F. 34, 145-1 58. 
RHOADES, M. M. 1942 .

Preferential segregation in maize.

Genetics 27, 395-407.

RIBBANDS, C. R. $\quad$ I 937 .

The consequences of structural hybridity at meiosis in Lilium $x$ testaceum.

J. Genet. 35, I-24.

SAMUELSON. I913.

Studien über die Entwicklungsgeschichte der Bluten einiger Bicornes typen.

Svensk. Bot. Tidsk. 7, 97-188.

SMITH-WHITE, s. I $947 a$.

A survey of chromosome numbers in the Epacridacea.

P. Linn. Soc. N.S.W. (in press).

SMITH-WHITE, s. 19476 .

Cytological studies in the Myrtacex. II. Chromosome numbers in the Leptospermoidex and Myrtoidex.

P. Linn. Soc. N.S.W. (in press).

STURTEVANT, A. H. I936.

Preferential segregation in Triplo-IV females of Drosophila melanogaster.

Genetics 21, 444-466.

TÄcкноцM, G. 1922 .

Zytologische Studien über die Gattung Rosa.

Acta Hort. Berg. 7, 97-381.

WANSCHER, J. H. I934.

Secondary associations in the Umbelliferæ and Bicornes.

New Phyt. 33, 58-65. 